\title{
Factors associated with the perceived barriers of health care access among reproductive-age women in Ethiopia: a secondary data analysis of 2016 Ethiopian demographic and health survey
}

Koku Sisay Tamirat ${ }^{*}$, Zemenu Tadesse Tessema ${ }^{1}$ and Fentahun Bikale Kebede ${ }^{2}$

\begin{abstract}
Background: Health care access is the timely use of personal health services to achieve the best health outcomes. Problems in accessing health care among reproductive-age may lead to various adverse health outcomes like death and disabilities. Therefore, this study aimed to identify factors associated with the perceived barriers of healthcare access among reproductive-age women in Ethiopia.

Method: This study was based on secondary data sources from the 2016 Ethiopia Demography and Health Survey. The individual women record (IR) file was used to extract about 15, 683 women for the final analysis from the largest dataset. A composite variable of health care access was created from four questions used to rate health care access problems among women of reproductive age. To identify factors associated with the perceived barriers of health care access among reproductive-age women, generalized estimating equation (GEE) model was fitted. Crude and adjusted odds ratio (AOR) with a 95\% confidence interval (CI) computed to assess the strength of association between independent and outcome variables.
\end{abstract}

Results: This study revealed that the magnitude of perceived barriers of healthcare access among reproductive-age women was $69.9 \%$ with $95 \% \mathrm{Cl}(69.3$ to 70.7$)$ to at least one or more of the four reasons. Rural resident ( $\mathrm{AOR}=2.13$, 95\%Cl: 1.79 to 2.53 ), age $35-49$ years $(A O R=1.24,95 \% C l: 1.09$ to 1.40$)$, divorced/separated $(A O R=1.34,95 \% \mathrm{Cl}: 1.17$ to 1.54 ), had no health insurance coverage ( $\mathrm{AOR}=1.19,95 \% \mathrm{Cl}: 1.01$ to 1.45 ), poorer ( $\mathrm{AOR}=2.09,95 \% \mathrm{Cl}: 1.86$ to 2.35 ) and middle wealth ( $\mathrm{AOR}=1.57,95 \% \mathrm{Cl}: 1.38$ to 1.79 ), no education ( $\mathrm{AOR}=2.30,95 \% \mathrm{Cl}: 1.95$ to 2.72 ), primary education ( $\mathrm{AOR}=1.84,95 \% \mathrm{Cl}: 1.58$ to 2.15 ) and secondary education ( $\mathrm{AOR}=1.31,95 \% \mathrm{Cl}: 1.13$ to 1.51 ) were factors associated with the perceived barriers of health care access.

(Continued on next page)

\footnotetext{
* Correspondence: kokusisay23@gmail.com

'Department of Epidemiology and Biostatistics, Institute of Public Health, College of Medicine and Health Sciences, University of Gondar, Gondar, Ethiopia

Full list of author information is available at the end of the article
}

(C) The Author(s). 2020 Open Access This article is licensed under a Creative Commons Attribution 4.0 International License, which permits use, sharing, adaptation, distribution and reproduction in any medium or format, as long as you give appropriate credit to the original author(s) and the source, provide a link to the Creative Commons licence, and indicate if changes were made. The images or other third party material in this article are included in the article's Creative Commons licence, unless indicated otherwise in a credit line to the material. If material is not included in the article's Creative Commons licence and your intended use is not permitted by statutory regulation or exceeds the permitted use, you will need to obtain permission directly from the copyright holder. To view a copy of this licence, visit http://creativecommons.org/licenses/by/4.0/ The Creative Commons Public Domain Dedication waiver (http://creativecommons.org/publicdomain/zero/1.0/) applies to the data made available in this article, unless otherwise stated in a credit line to the data. 


\begin{abstract}
(Continued from previous page)
Conclusion: A significant proportion of women of reproductive age faced barriers to healthcare access, of which money and distance were the most frequently perceived barriers. Divorced/separated marital status, old age, rural dwelling, no health insurance coverage, low economic situation, and level of education were factors associated with perceived barriers. These findings suggest further strengthening and improving health care access to those women with low socio-economic status for the realization of universal health coverage.
\end{abstract}

Keywords: Perceived barriers, Healthcare access, Women, Ethiopia

\section{Background}

In the past two decades, maternal health status showed a noteworthy improvement and achievements of Millennium Development Goals (MDGs), which was reflected by maternal and child mortality [1]. According to the 2015 MDGs report, maternal and under-five children mortality had decreased by 45 and $52 \%$, respectively, from the 1990 baseline figs [1].. However, maternal health problems are still a significant concern and are unfinished agendas of MDG for low-income countries like Africa [1,2]. Ethiopia is a highly affected country with the highest maternal and child mortality among sub-Saharan countries, with an estimated 353 deaths per 100,000 live births, according to the 2015 report [3]. Similarly, according to the Ethiopia 2016 national survey, institutional delivery was 66 , and $22 \%$ of women had an unmet need for family planning services, which was linked to various barriers of accessibility and utilization [3]. Despite, all the United Nations (UN) member states have agreed to achieve universal health coverage by 2030 as part of SDGs; still half of the global population doesn't have full coverage for essential health care services $[4,5]$.

Access to health care broadly defined based on availability, affordability, accessibility, and acceptability of services for best health outcomes [6]. Access to allinclusive and quality health care is essential for promoting and maintaining health, preventing and managing the diseases, reducing unnecessary disabilities and premature deaths, and achieving health equity for all women [7-10]. Moreover, reproductive, maternal, newborn, and child health are indicators of the country's socio-economic status and equitable o distribution of health care in the community [11-15].

It is known that literacy levels, economic conditions, socio-demographic and cultural characteristics, and geographical disparities play a vital role in affecting the accessibility and utilization of healthcare services among women [16-20]. Troubles conditions in accessing health care among reproductive-age women lead to diverse adverse health outcomes like unwanted pregnancies, unsafe abortion, maternal and child mortality resulting from low family planning uptakes, and home deliveries $[7,9,14,15,21]$.
The Federal Democratic Republic of Ethiopia has a three-tier healthcare system, ranging from the lowest primary health care unit that provides essential health services to the highest tertiary hospitals for specialized services. Specifically, the primary health care units had components like health posts, which is mainly intended to provide essential health services (antenatal, postnatal and family dispenses, and immunization) to the population within five kilometers of radius by using health extension workers [22]. Establishing mobile maternal health clinics and expansion of health facilities and providing maternal health care services free of charge, are some of the interventions used to increase the service accessibility and utilization [23]. Literature showed that rural residents, low levels of education, financial hardship, and unemployment were factors associated with the challenges of health care access among reproductiveage women [12, 14-16, 18-20, 24]. A better understanding of the health care access difficulties using nationally representative data might assist in problem-solving and decision-making processes. Though many studies had been conducted to assess health care access challenges at different sites, no research has been to identify factors allied to difficulties of health care access among reproductive-aged women using national representative data.

Therefore, this study aimed to identify factors associated with the perceived barriers of healthcare access among reproductive-age women in Ethiopia. This study's findings could help health care policymakers improve the health care of women through service redistribution to achieve equity of health care.

\section{Methods}

\section{Data source}

This study was based on secondary data analysis from the 2016 Ethiopia Demographic and Health Survey, which was collected cross-sectionally from January 18, 2016, to June 27, 2016. The study was conducted in Ethiopia, located in the Horn of Africa. The country has nine Regional states (Afar, Amhara, BenishangulGumuz, Gambela, Harari, Oromia, Somali, Southern Nations, Nationalities, and People's Region (SNNP) and 
Tigray) and two Administrative Cities (Addis Ababa and Dire-Dawa).

\section{Population and samples}

For the sampling purposes, the nine regional and two city administrations of Ethiopia were stratified into urban and rural enumeration areas, of which 202 and 443 EAs were initially selected from urban and rural areas, respectively, by probability sampling method. Then, a fixed number of 28 households per cluster were systematically selected. In the interviewed households, 16,583 eligible women identified for interviews of which, 15,683 women had completed the interview and included in the final analysis. The study participants from each EA stratum selected independently by using the probability sampling technique. The detail of the methodology is available in the full report of 2016 EDHS [3].

\section{Measurement of variables}

Five data collection questionnaires were used for the 2016 EDHS, women's questionnaire was one of the tools used to collect data about women and child health characteristics. For this study, women's Individual Record (IR) file was used to extract, socio-demographic and reproductive traits were extracted from the most substantial dataset.

The Perceived barriers to health care access were the response variable. On the other hand, age, residence, wealth (economic) status, level of education, marital status, working status, health insurance coverage, and reproductive characteristics such as contraceptive use and intention, place of delivery, ANC follow up, and pregnancy during data collection were independent variables.

Each woman was interviewed to rate the difficulties of accessing health care based on obtaining money, health facility's distance, permission to consult the doctor, and not wanting to go alone. Women reported at least one challenge of healthcare access (money, distance, companionship, and permission) considered as having perceived barriers of health care access, which coded as " 1 ". On the other hand, if a woman didn't report challenges of the obstacles mentioned above, like obtaining money, distance, companionship, and permission, it was considered no perceived barrier to health care access, coded as "0" [3, 12].

\section{Data management and analysis}

The data were weighted using sampling weight, primary sampling unit, and strata before any statistical analysis to restore the representativeness of the survey and take into account the sampling design to get reliable statistical estimates. Descriptive and summary statistics were conducted using STATA version 14 software. To identify factors associated with the perceived barriers of health care access among reproductive-age women, generalized estimating equation (GEE) model was fitted [25]. The data nature of EDHS showed that women were nested within a cluster, and those who reside within the same clusters were correlated to each other compared to the other clusters. This data showed that the Intra Class Correlation (ICC) was calculated and found to be $40 \%$ indicated a correlation among observations in the clusters. These violated the conditional logistic regression model's assumptions that consider the independence of observations and equal variance across clusters. The Generalized Estimating Equation (GEE) model was fitted with a logit link function and binomial family and working correlation structures of independent, exchangeable, unstructured, and autoregressive compared simultaneously. The model with the smallest standard error differences between robust and modelbased standard errors that were the model with the exchangeable correlation structure was selected. To assess the strength of association between outcome and independent variables crude and adjusted odds ratio with a $95 \%$ confidence interval (CI) computed and presented on the table. Variables had less than 5\% p-value in the multivariable GEE model considered independent factors associated with the perceived barriers of health care access.

\section{Model comparison}

In this study, we fitted two models GEE which is a marginal model that considers correlation among clusters and a conventional logistic regression model with a robust standard error that also controlled for withincluster correlations. To select the best-fitted model, we used quasi information criteria (QIC) for the model comparison and the result presented on the Table 1 as follow.

\section{Result}

Socio-demographic characteristics

A total of 15,683 reproductive-age women were included in the final analysis of the study. The median age of women was 27 with (IQR: 20 to 35) years; nearly two-thirds $(67.5 \%)$ of women gave birth previously, and 18 years is the median age to the first birth. More than three-four (77.8\%) women were rural dwellers, $47.8 \%$ had no formal education, $63.8 \%$

Table 1 Model comparison

\begin{tabular}{lc}
\hline Types of the model fitted & QIC \\
\hline GEE & 18,301 \\
Conventional logistic & 18,441 \\
\hline The GEE had the smallest QIC it better fits the data than the conventional
\end{tabular}
logistic regression model. 
were married, $46.3 \%$ rich wealth index, and $43.2 \%$ were orthodox Christians. The majority (94.7\%) of women had no health insurance coverage; among interviewed women, $7.2 \%$ of them were pregnant during data collection, and $41.6 \%$ of them visited health facilities in the past 12 months (Table 2).

\section{Correlation between perceived barriers of health care access and reproductive health services}

The chi-square analysis showed a correlation between reproductive health service (contraceptive utilization history, place of delivery, and previous ANC follow-up). The reproductive variables cannot be included in the

Table 2 Socio demographic and reproductive characteristics of women who aged 15-49years in Ethiopia, $2016(n=15,683)$

\begin{tabular}{|c|c|c|c|}
\hline Characteristics & Category & Frequency & Percentage \\
\hline \multirow[t]{3}{*}{ Age in years } & $15-19$ & 3381 & 21.6 \\
\hline & $20-34$ & 8064 & 51.4 \\
\hline & $35-49$ & 4238 & 27 \\
\hline \multirow[t]{2}{*}{ Residence } & Urban & 3476 & 21.2 \\
\hline & Rural & 12,207 & 77.8 \\
\hline \multirow[t]{4}{*}{ Religion } & Orthodox & 6786 & 43.3 \\
\hline & Muslim & 4893 & 31.2 \\
\hline & Protestant & 3674 & 23.4 \\
\hline & Other & 330 & 2.1 \\
\hline \multirow[t]{4}{*}{ Education level } & No formal education & 7498 & 49 \\
\hline & Primary school & 5490 & 35 \\
\hline & Secondary school & 1818 & 11.5 \\
\hline & Diploma and above & 877 & 5.5 \\
\hline \multirow[t]{3}{*}{ Marital status } & Never married & 4037 & 25.7 \\
\hline & Married/living together & 10,223 & 65.2 \\
\hline & Divorce/widowed/separated & 1423 & 9.1 \\
\hline \multirow[t]{3}{*}{ Wealth index } & Poor & 5442 & 34.7 \\
\hline & Middle & 2978 & 19 \\
\hline & Rich & 7263 & 46.3 \\
\hline \multirow[t]{2}{*}{ Gave birth in the last five years } & Yes & 7590 & 48.4 \\
\hline & No & 8093 & 51.6 \\
\hline \multirow[t]{2}{*}{ Place of delivery $(n=7590)$} & Home & 5066 & 66.7 \\
\hline & Health facility & 2524 & 33.3 \\
\hline \multirow[t]{2}{*}{ Had ANC follow up $(n=7590)$} & Yes & 2818 & 37.1 \\
\hline & No & 4772 & 63.9 \\
\hline \multirow[t]{2}{*}{ Contraceptive use and intention } & Yes & 3974 & 25.34 \\
\hline & No & 11,708 & 74.66 \\
\hline \multirow[t]{2}{*}{ Visited health facility in the last 12 months } & Yes & 6526 & 41.6 \\
\hline & No & 9157 & 58.4 \\
\hline \multirow[t]{2}{*}{ Sex of household head } & Male & 11,960 & 76.3 \\
\hline & Female & 3723 & 23.7 \\
\hline \multirow[t]{2}{*}{ History of abortion } & No & 14,447 & 92.1 \\
\hline & Yes & 1326 & 7.9 \\
\hline \multirow[t]{2}{*}{ Working status } & Working & 5220 & 33.3 \\
\hline & Not working & 10,463 & 66.7 \\
\hline \multirow[t]{2}{*}{ Ever heard of fistula } & Yes & 5990 & 38.4 \\
\hline & No & 9625 & 61.6 \\
\hline \multirow[t]{2}{*}{ Health insurance coverage } & Yes & 830 & 5.3 \\
\hline & No & 14,853 & 94.7 \\
\hline \multirow[t]{2}{*}{ Currently pregnant } & No & 14,547 & 92.8 \\
\hline & Yes & 1135 & 7.2 \\
\hline
\end{tabular}


GEE marginal analysis model because no use of these services may not be an indicator of health care perceived barriers (Table 3).

\section{Perceived barriers of health care access among reproductive-age women}

In this study, more than two-thirds (69.9, 95\%CI: 69.3 to 70.7) of reproductive-age women had at least one perceived barrier to access health care, of which money (54.8\%), the distance of health facilities $(50.3 \%)$ were the most frequently mentioned challenges. Furthermore, out of the currently pregnant women during the data collection time, about $73 \%$ of them had perceived barriers to healthcare access. Of the parameters used to assess perceived barriers of healthcare access, about $21.5 \%$ of women had multiple challenges (money, distance, companionship, and permission) (Fig. 1).

\section{Factors associated with perceived barriers of health care access}

The result of the bi-variable analysis showed that all explanatory variables were associated with healthcare access's perceived barriers at a $20 \%$ level of significance. The multivariable generalized estimated equation (GEE) model showed that variables like residence, marital status, age group, educational level, wealth index, and health insurance were significant determinants of perceived barriers of health care access at a $5 \%$ level of significance (Table 4).

Those women who reside in rural areas were 2.13 times more likely to had perceived barriers of health care access than urban residents $(\mathrm{AOR}=2.13,95 \% \mathrm{CI}$ : 1.79 to 2.53$)$. Similarly, women aged $35-49$ years, the odds of perceived barriers to access health care were 1.24 times higher than those aged 15-19 years $(\mathrm{AOR}=1.24,95 \% \mathrm{CI}: 1.09$ to 1.40$)$. The likelihood of having perceived barriers to access health care among divorced/separated women was increased by $34 \%$ compared to married/live together $(\mathrm{AOR}=1.34$, 95\%CI: 1.17 to 1.54 ). Similarly, the odds of perceived challenges of health care access to those who had no formal education $(\mathrm{AOR}=2.30,95 \% \mathrm{CI}: 1.95$ to 2.72 ), primary $(\mathrm{AOR}=1.84,95 \% \mathrm{CI}: 1.58$ to 2.15$)$ and secondary ( $\mathrm{AOR}=1.31,95 \% \mathrm{CI}$ : 1.13 to 1.51 ) higher compared to those who attended college and above. For women who had poor and middle wealth status, the odds of perceived barriers of health care access were 2.09 and 1.57 times higher, compared to wealthier women, respectively (AOR $=2.09,95 \%$ CI: $1.86,2.35$ ) and $(\mathrm{AOR}=1.57,95 \% \mathrm{CI}: 1.38,1.79)$. Those women who had no health insurance coverage, the odds of perceived barriers of health care access increased by $19 \%$ compared to those insured $(\mathrm{AOR}=1.19,95 \% \mathrm{CI}$ : 1.01, 1.45) (Table 3).

\section{Discussion}

This study revealed that about $70 \%$ of women of reproductive age had perceived barriers of health care access due to at least one or more of the four reasons, of which difficulty of obtaining money and distance from health facilities were the most frequently mentioned barriers. The present study magnitude was significantly lower than previous EDHS reports of (95.7\%) in 2005 [26] and (93.6\%) in 2011 [27]. The Ethiopia government has made tremendous efforts to achieve millennium development goals of reducing maternal and child mortality, which might contribute to lower perceived barriers of health care among women. Additionally, the country's economic growth in the last 15 years and it's policy revision to provide basic maternal and child health services free of charge as exempted by the government may also contribute to the decline of perceived barriers among women $[22,23,28]$.

However, the current study result showed a higher magnitude of perceived barriers, despite the global efforts for universal health access for all world peoples. Moreover, this finding was more elevated than study reports from Tanzania 65\% [12] and 64.5\% in South Africa [29]. This could be explained socio-cultural and economic difference among countries which may affect health-seeking behaviors. In general, despite $100 \%$ health facility coverage per population, different barriers are

Table 3 The association between perceived barriers and reproductive health services using EDHS 2016

\begin{tabular}{|c|c|c|c|c|c|}
\hline \multirow[t]{2}{*}{ Reproductive health services } & & \multicolumn{2}{|c|}{ perceived barriers of health care access } & \multirow{2}{*}{$\begin{array}{l}\text { Chi- } \\
\text { square(1) }\end{array}$} & \multirow{2}{*}{$\begin{array}{l}p- \\
\text { value }\end{array}$} \\
\hline & & Big problem & Not a big problem & & \\
\hline \multirow[t]{2}{*}{ Contraceptive utilization history } & Yes & 8051 & 5151 & 252 & $<0.001$ \\
\hline & No & 2033 & 448 & & \\
\hline \multirow[t]{2}{*}{ Place of delivery for the recent child } & Institution & 1351 & 1247 & 471 & $<0.001$ \\
\hline & Home & 3493 & 902 & & \\
\hline \multirow[t]{2}{*}{ Had previous ANC follow up } & Yes & 3011 & 1701 & 252 & $<0.001$ \\
\hline & No & 2033 & 448 & & \\
\hline
\end{tabular}




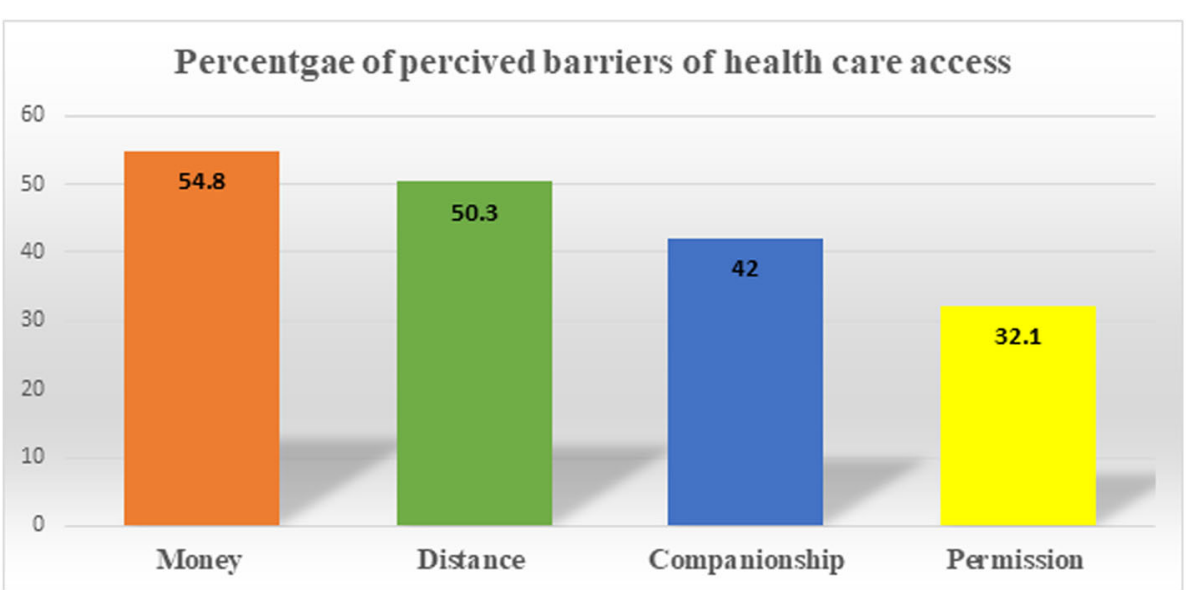

Fig. 1 Percentage of perceived barriers of health care access among reproductive-age women in Ethiopia, 2016

responsible for timely access and utilization of health care services among reproductive-age women, which made doubts about the achievement of SDGs universal reproductive health access and equitable distribution of services.

Personal and organizational characteristics attributed $\mathrm{w}$ with the perceived barriers of health care access among reproductive-aged women. Thus, women who reside in rural areas, the odds of perceived barriers of health care access were two times higher than in urban dwellings. This finding was consistent in previous studies in Tanzania, Ghana, and South Africa [12, 16, 29 ]. These could be due to the fact rural areas are associated with lower geographical accessibility of health facilities. Besides economic problems, there are also socio-cultural issues related to lower male involvement and support for women's healthcare access. Older age (35-49 years) women were associated with increased perceived barriers of health care access compared to Youngers. This could be because women of the older generation may be affected by distance travel to obtain healthcare in peripheral areas. Also, financial hardship and dependency are higher at an older age compared to younger ones.

Divorced/separated women had increased barriers to health care access compared to a married one. This finding was in line with previous studies [12, 18, 19]. These could be explained by those married women who may have better economic and psychosocial support from their partners to access health care [30]. Indirectly, married women may have decided collectively to control their family size and fertility behavior, which could impact the health care access of a woman.

Similarly, women had no health insurance coverage associated with increased odds of health care access problems. This finding was consistent with previous studies [31]. Community-based health insurance has been implemented in Ethiopia since 2010 that protects the individual from unexpected catastrophic expenditure and minimize difficulties in obtaining money for consultation of the doctor [31]. Likewise, lower educational status below is associated with increased perceived barriers of health care access among women of reproductive age. Better educational levels may improve awareness and increase health-seeking behavior among reproductive-age women. This finding was consistent with other studies [12, 16, 19, 32].

This work also reported that Women who had financial hardships like poor and middle wealth class associated with an increased perceived barrier of healthcare access compared to riches. This finding was consistent with the previous study conducted in Tanzania [12]. These possible reasons might be that women who had a better wealth index may help them access health care for their best health outcomes. Besides, a better wealth index may reduce the difficulties of obtaining money to access health care.

This study has strengths of nationally representative data, and advanced statistical models were used to account correlations within clusters. However, this study has limitations of the survey's cross-sectional nature, and spatial variability was not assessed. Also, the effects of the health system and health care worker factors were not addressed.

\section{Conclusions}

A significant proportion of reproductive-age women faced barriers of health care access, of which, money and distance were the commonly perceived barriers. Divorced/separated marital status, old age, rural dwelling, no health insurance coverage, low economic situation, 
Table 4 Bivariable and multivariable generalized estimating equation (GEE) regression analysis reproductive age group women in Ethiopia, $2016(n=15,683)$

\begin{tabular}{|c|c|c|c|c|}
\hline \multirow[t]{2}{*}{ Characteristics } & \multicolumn{2}{|c|}{ Health care access problem } & \multirow{2}{*}{$\begin{array}{l}\text { Crude odds } \\
\text { ratio }(95 \% \mathrm{Cl})\end{array}$} & \multirow{2}{*}{$\begin{array}{l}\text { Adjusted OR } \\
(95 \% \mathrm{Cl})\end{array}$} \\
\hline & $\overline{\text { Yes }}$ & No & & \\
\hline \multicolumn{5}{|l|}{ Residence } \\
\hline Urban & 1584 & 1892 & 1 & 1 \\
\hline Rural & 9392 & 2814 & $4.00(3.40,4.70)$ & $2.13(1.79,2.53)^{*}$ \\
\hline \multicolumn{5}{|l|}{ Household head } \\
\hline Male & 8466 & 3495 & 1 & 1 \\
\hline Female & 2511 & 1211 & $1.11(1.04,1.19)$ & $1.05(0.97,1.11)$ \\
\hline \multicolumn{5}{|l|}{ Marital status } \\
\hline Married/living together & 7345 & 2877 & 1 & 1 \\
\hline Never married & 2592 & 1443 & $0.98(0.91,1.06)$ & $1.13(0.95,1.25)$ \\
\hline Divorced/widowed/separated & 1038 & 384 & $1.37(1.22,1.54)$ & $1.34(1.17,1.54)^{*}$ \\
\hline \multicolumn{5}{|l|}{ Age group } \\
\hline $15-19$ & 2291 & 1089 & 1 & \\
\hline $20-34$ & 5582 & 2481 & $1.014(0.94,1.09)$ & $1.06(0.99,1.23)$ \\
\hline $35-49$ & 3103 & 1135 & $1.21(1.11,1.32)$ & $1.24(1.09,1.40)^{*}$ \\
\hline \multicolumn{5}{|l|}{ Level of education } \\
\hline Diploma and above & 349 & 527 & 1 & 1 \\
\hline No formal education & 5847 & 1650 & $2.74(2.37,3.17)$ & $2.30(1.95,2.72)^{*}$ \\
\hline Primary education & 3906 & 1584 & $1.99(1.74,2.28)$ & $1.84(1.58,2.15)^{*}$ \\
\hline Secondary education & 873 & 943 & $1.33(1.17,1.52)$ & $1.31(1.13,1.51)^{*}$ \\
\hline \multicolumn{5}{|l|}{ Working status } \\
\hline Working & 3407 & 1812 & $0.96(0.90,1.02)$ & $0.99(0.92,1.06)$ \\
\hline Not working & 7569 & 2893 & 1 & 1 \\
\hline \multicolumn{5}{|l|}{ Wealth status } \\
\hline Rich & 4101 & 3161 & 1 & 1 \\
\hline Poor & 4574 & 867 & $2.72(2.46,3.02)$ & $2.09(1.86,2.35)^{*}$ \\
\hline Middle & 2300 & 677 & $1.92(1.71,2.16)$ & $1.57(1.38,1.79)^{*}$ \\
\hline \multicolumn{5}{|l|}{ Health insurance } \\
\hline Insured & 460 & 369 & 1 & 1 \\
\hline Non-insured & 10,551 & 4337 & $1.27(1.05,1.53)$ & $1.19(1.01,1.45)^{*}$ \\
\hline \multicolumn{5}{|l|}{ Gave birth in the last five years } \\
\hline Yes & 3288 & 2804 & 1 & 1 \\
\hline No & 5688 & 1901 & $1.07(1.01,1.14)$ & $1.09(0.98,1.19)$ \\
\hline \multicolumn{5}{|l|}{ Ever heard of fistula } \\
\hline Yes & 7395 & 2229 & 1 & 1 \\
\hline No & 3521 & 2468 & $0.73(0.68,0.78)$ & $0.79(0.75,1.05)$ \\
\hline
\end{tabular}

* shows statistical significan;ce at $p$-value less than 0.05

and level of education were factors associated with perceived barriers of health care access. These findings suggest that further strengthening and redistribution of health care services to those with low socio-economic status for the attainment of universal health coverage and equity of health.

\section{Abbreviations}

ANC: Antenatal Care; AOR: Adjusted Odds Ratio; Cl: Confidence Interval; EA: Enumeration Areas; EDHS: Ethiopia Demography and Health Survey; GEE: Generalized Estimating Eq.; ICC: Intra Class Correlation; IQR: Interquartile range; IR: Individual Record; MDG: Millennium Development Goals;

QIC: Quasi-likelihood Information Criteria; SDG: Sustainable Development Goals 


\section{Acknowledgments}

We would like to thank the Ethiopian Central Statistics Agency for all the relevant secondary data used in this study. Finally, we would like to thank all who directly or indirectly supported us.

\section{Authors' contributions}

KST, ZTT, and FBK conceived the study, involved in the study design, data analysis, drafted the manuscript, and critically reviewed the manuscript. All authors read and approved the final manuscript.

\section{Funding}

We didn't receive external fund for this research.

\section{Availability of data and materials}

The data analyzed for this study is from the Ethiopian Demographic and Health Survey and accessible with permissions from the measure DHS.

\section{Ethics approval and consent to participate}

Ethical clearance was obtained from measure DHS through filling requesting a form for accessing data at www.measuredhs.com. The data used in this study are publicly available, aggregated secondary data with no personal identifying information that can be linked to study participants. The confidentiality of data was maintained anonymously.

\section{Consent for publication}

Not applicable.

\section{Competing interests}

The authors declared that they have no competing interests.

\section{Author details}

'Department of Epidemiology and Biostatistics, Institute of Public Health, College of Medicine and Health Sciences, University of Gondar, Gondar, Ethiopia. ${ }^{2}$ Amhara Regional State Health Bureau, Gondar, Ethiopia.

Received: 21 August 2019 Accepted: 29 June 2020

Published online: 25 July 2020

\section{References}

1. Way C. The millennium development goals report 2015. UN; 2015

2. Kumar S, Kumar N, Vivekadhish S. Millennium development goals (MDGS) to sustainable development goals (SDGS): addressing unfinished agenda and strengthening sustainable development and partnership. Indian J Community Med. 2016:41(1):1.

3. Central Statistical Agency, Ethiopia demographic and health survey 2016, in ORC Macro, Calverton, Maryland, USA. 2016.

4. Organization, W.H. Monitoring health for the SDGs: sustainable development goals. Geneva: World Health Organization; 2016.

5. Organization, W.H., Moving ahead with universal health coverage and other health SDG targets in countries of the African region. 2018

6. Gulliford $M$, et al. What does' access to health care'mean? J Health Serv Res Policy. 2002;7(3):186-8

7. Erasmus MO. The barriers to access for maternal health care amongst pregnant adolescents in the Mitchells plain sub-district; 2017.

8. Munthali $\mathrm{AC}$, et al. "This one will delay us": barriers to accessing health care services among persons with disabilities in Malawi. Disabil Rehabil. 2019 41(6):683-90.

9. Rutherford ME, Mulholland K, Hill PC. How access to health care relates to under-five mortality in sub-Saharan Africa: systematic review. Tropical Med Int Health. 2010;15(5):508-19.

10. Washington $\mathrm{DL}$, et al. Access to care for women veterans: delayed healthcare and unmet need. J Gen Intern Med. 2011;26(2):655.

11. Audibert, M. and J. Mathonnat, Facilitating access to healthcare in lowincome countries: a contribution to the debate. Field Actions Science Reports. The journal of field actions, 2013(Special Issue 8).

12. Bintabara D, Nakamura K, Seino K. Improving access to healthcare for women in Tanzania by addressing socio-economic determinants and health insurance: a population-based cross-sectional survey. BMJ Open. 2018;8(9): e023013.

13. Bloom, G., et al., 2030 AGENDA FOR SUSTAINABLE DEVELOPMENT deliberate next steps toward a new globalism for universal Health Coverage (UHC).
14. Nyakang'o SB, Booth A. Women's perceived barriers to giving birth in health facilities in rural Kenya: a qualitative evidence synthesis. Midwifery. 2018;67:1.

15. Viveiros CJ, Darling EK. Barriers and facilitators of accessing perinatal mental health services: the perspectives of women receiving continuity of care midwifery. Midwifery. 2018;65:8-15.

16. Badu $E$, et al. Enablers and barriers in accessing sexual and reproductive health services among visually impaired women in the Ashanti and Brong Ahafo regions of Ghana. Reprod Health Matters. 2018;26(54):51-60.

17. Ir $P$, et al. Using targeted vouchers and health equity funds to improve access to skilled birth attendants for poor women: a case study in three rural health districts in Cambodia. BMC Pregnancy Childbirth. 2010;10(1):1.

18. Kea $A Z$, et al. Exploring barriers to the use of formal maternal health services and priority areas for action in Sidama zone, southern Ethiopia. BMC Pregnancy Childbirth. 2018;18(1):96.

19. King $R$, et al. Barriers and facilitators to accessing skilled birth attendants in Afar region, Ethiopia. Midwifery. 2015;31(5):540-6.

20. Okwaraji $\mathrm{YB}$, Webb EL, Edmond KM. Barriers in physical access to maternal health services in rural Ethiopia. BMC Health Serv Res. 2015;15(1):493.

21. Ayanore MA, Pavlova M, Groot W. Unmet reproductive health needs among women in some west African countries: a systematic review of outcome measures and determinants. Reprod Health. 2015;13(1):5.

22. Admasu K, Balcha T, Ghebreyesus TA. Pro-poor pathway towards universal health coverage: lessons from Ethiopia. J Glob Health. 2016;6(1):010305.

23. Lemma, S., et al., How to improve maternal health service utilisation in Ethiopia. 2018

24. Olayinka $\mathrm{OA}$, et al. Awareness and barriers to utilization of maternal health care services among reproductive women in Amassoma community, Bayelsa state. Int J Nurs Midwifery. 2014;6(1):10-5.

25. Lipsitz $\mathrm{S}$, et al. One-step generalized estimating equations with large cluster sizes. J Comput Graph Stat. 2017;26(3):734-7.

26. Central Statistical Agency (CSA) [Ethiopia] and ICF. Ethiopia Demographic and Health Survey 2005. Addis Ababa, Ethiopia; 2005.

27. Central Statistical Agency [Ethiopia] and ICF International, Ethiopia Demographic and Health Survey 2011. 2012

28. World Health Organization. Universal access to reproductive health: accelerated actions to enhance progress on Millennium Development Goal 5 through advancing Target 5B. World Health Organization; 2011.

29. Silal SP, et al. Exploring inequalities in access to and use of maternal health services in South Africa. BMC Health Serv Res. 2012;12(1):120.

30. Ani $F$, et al. Demographic factors related to male involvement in reproductive health care services in Nigeria. Eur J Contracept Reprod Health Care. 2016:21(1):57-67.

31. Mekonen AM, Gebregziabher MG, Teferra AS. The effect of community based health insurance on catastrophic health expenditure in Northeast Ethiopia: a cross sectional study. PLoS One. 2018;13(10):e0205972.

32. Munguambe $K$, et al. Barriers and facilitators to health care seeking behaviours in pregnancy in rural communities of southern Mozambique. Reprod Health. 2016;13(1):31.

\section{Publisher's Note}

Springer Nature remains neutral with regard to jurisdictional claims in published maps and institutional affiliations.

Ready to submit your research? Choose BMC and benefit from

- fast, convenient online submission

- thorough peer review by experienced researchers in your field

- rapid publication on acceptance

- support for research data, including large and complex data types

- gold Open Access which fosters wider collaboration and increased citations

- maximum visibility for your research: over $100 \mathrm{M}$ website views per year

At BMC, research is always in progress.

Learn more biomedcentral.com/submissions 